\title{
El ojo de la cámara y la retórica de la imagen
}

\author{
Christian Bonnet"
}

Profesor de Psicopatología clínica Aix-Marseille Université

Recibido: 10 de enero 2018; aceptado: 5 de marzo 2018

\begin{abstract}
Resumen
El artículo se basa en una clínica analítica con adolescentes que traen películas a las sesiones. Luego, se toman los temas de la memoria y del recuerdo en sus aspectos freudianos clásicos; tanto como los lazos y las distancias que existen entre Freud, el cine y el psicoanálisis. La retórica (en el sentido de Yates y de Arasse) está articulada con la figuración para proponer así una aproximación clásica en el campo estructuralista (Barthes, Foucault) entre discurso y cine. El autor propone entonces una articulación específica entre retórica, estética y compromiso político en el cine. Los recursos del análisis estructural de los relatos conducen a proponer un modelo de las fórmulas narrativas del tema de las luchas. Finalmente, se propone una apertura al evocar la expresión de ojo de la cámara y ligándola al concepto de análisis fílmico de la mirada a la cámara (Vernet) para proponer en fin la concepción de mirada a través de la cámara. Esta sería una modalidad original, específica de los procesos adolescentes, dado que el adolescente se expone a la imagen que "lo mira” y, fundamentalmente, el artículo indica que: Esta mirada a través de la cámara está anudada a la transferencia.
\end{abstract}

Palabras Clave: Memoria | Retórica | Ética | Análisis estructural | Mirada a la cámara | Mirada a través de la cámara

The eye of the camera and the rhetoric of the image

\begin{abstract}
The article is based on an analytic clinical of adolescents mobilizing in film sessions. Next, the themes of memory and recollection in their Freudian aspects are classically considered; as well as the links and distances between Freud, cinema and psychoanalysis. The rhetoric (in the sense of Yates and Arasse) is articulated with the figuration to propose a classical connection in the structuralist field (Barthes, Foucault) between speech and cinema. The author proposes a specific articulation between rhetoric, aesthetics and political engagement in the cinema. The resources of the structural analysis of the narratives lead to propose a model of the narrative formulas of the theme of the struggles. Finally a singular opening is proposed by mobilizing the expression of the eye to the camera and linking it to the concept of film analysis of the look at the camera (Vernet) to propose the design of the look by the camera. This one would be an original modality, specific of the adolescent processes, as the adolescent exposes himself to the image which "looks at him" and especially the article indicates that: This look by the camera is tied to the transfer.
\end{abstract}

Key Words: Memory | Rhetoric | Ethics | Structural Analysis | Looking at the camera | Looking by the camera

\section{Una clínica}

En mi clínica freudiana muchos adolescentes vienen a la sesión con arrebatos, tristezas, enojos, incluso con sufrimientos y llantos mezclados con gritos de rabia; y esto después de haber encontrado en desvíos nocturnos películas de bordes y aristas duros e incisivos; películas que desgarran el material de los desconocimientos adolescentes.

Natacha vio Noche y niebla y llorará lenta y sostenidamente durante una gran parte de la sesión.

Alfred ríe, incluso casi hasta las lágrimas, desde su descubrimiento (internet mediante) de Olympia seguido del Triunfo de la voluntad.
Akira está dubitativo, preocupado y fascinado respecto del Nacimiento de una nación.

Mylène está agresiva y me ordena explícitamente a explicarle las frases de $S 21$.

Simon, abrumado, habiendo agotado sus lágrimas y con la voz quebrada querrá repetirme y comentarme los diálogos de Shoah.

Mélanie se levanta, hace la mímica, gesticula y reproduce actitudes y gestos sacados de las escenas del Acorazado Potemkin.

Algunos, como Simon, recitan diálogos, otros describen planos o escenas, otros imitan la música, algunos encarnan con el cuerpo gestos y actitudes de los personajes, muchos atrapan mi mirada y murmuran o dicen con un

xtian.bonnet@gmail.com 
tono áspero: “¿Qué es esto?”, “¿Qué vi?”, “¿Así somos nosotros?”

Y yo ahí estoy, en sesión, tironeado por esos discursos cuya intensidad me estremece. Me cuentan películas, se cuentan en esas películas, se cuentan y me cuentan en los relatos de películas, me cuentan mi propia verdad cuando era adolescente y también veía algunas de esas películas...

No voy a dejar entonces de examinar esos fragmentos preliminares de mi clínica en los que me apoyo. En este texto, cada vez que utilice el término genérico de "película” me remitiré a estas películas citadas y evocadas por los adolescentes; no se tratará nunca del cine en su historia sino más bien de ese cine convocado en el vacío de las sesiones, un cine político, comprometido, duro y enigmático a la vez.

Sin embargo, no voy a hablar ni analizar mucho más estas sesiones, no voy a ir más allá del lugar de la transferencia en estos discursos; sino que voy a tomar más bien algunos desvíos teóricos para formular también la esencia de mi ética.

\section{Memoria y recuerdo en el cine y en psicoanálisis}

Comenzaré entonces de manera muy clásica interrogando la memoria y el recuerdo (dado que ese fue el tema del coloquio) y esto desde el punto de vista del psicoanálisis freudiano.

La lectura de Freud -a la que suscribo (y que Gori 1996, 1999, nos transmitió tan claramente)- propone que el propio prototipo del recuerdo es un recuerdo encubridor, una pantalla, es decir una construcción que toma algunos vestigios pero que se forma fundamentalmente en el deseo inconsciente. Mientras la memoria es esencialmente inconsciente; de la articulación de estas dos propuestas surge que finalmente uno recuerda sólo para olvidar mejor y que uno olvida para recordar. La psicopatología de la vida cotidiana en relación a los olvidos y los recuerdos parece mostrarlo suficientemente bajo la pluma de Freud.

El cine de la memoria, o atravesado por las memorias, plantea tanto cuestiones sobre lo reprimido como sobre su retorno, pero también sobre el estatuto del acontecimiento en su dialéctica con el trauma, y, además, sobre los diversos lugares de la figurabilidad y la relación con el olvido.

¿Cómo pensar el cine, el olvido, la huella y la traza? Podríamos pensar ese cine evocado por los adolescentes como la estela conmemorativa, el exvoto, incluso la sepultura del acontecimiento y del sufrimiento surgido de las luchas. Sería entonces dar a ese cine de compromiso un valor de "representación" inmediata casi mimética. Iríamos entonces más fácilmente hacia un cine de compromiso que se aparenta a una construcción, reconstrucción de esta relación con la memoria de la "cosa", del acontecimiento, de las luchas tal como se transmiten y se cuentan a los que no fueron sus actores.

La función social de ese cine encontraría la función singular de un cine articulado al discurso psicoanalítico. Esto conduce a plantear el valor de discurso de ese cine; discurso de y en la cultura que revela su valor de estructura ideológica (las referencias a Foucault y a Barthes serán entonces soportes necesarios).

Tomémonos entonces un poco de tiempo para plantear dos preguntas clásicas pero que sólo bordean nuestra idea: ¿Qué hay de la posición de Freud respecto al cine y, recíprocamente, ¿cómo señalar la manera en la que el cine se sirve del psicoanálisis?

\section{Freud y el cine en cuatro fechas}

Debemos retomar cuatro referencias entre los clásicos que todos nosotros evocamos regularmente para significar la desconfianza e incluso el rechazo que manifestaba Freud respecto al cine tomado como evocación o ilustración del Psicoanálisis naciente.

Primero, 1900: el modelo del sueño y la expresión tan feliz de la pantalla del sueño constituye un punto citado frecuentemente; agregaremos el recurso a la figurabilidad como trabajo que permite acercar las condiciones de la fábrica a la imagen en escenas, y muchos de nosotros navegamos entre fórmulas como por ejemplo que el sueño no es una película y, sin embargo, ciertas películas se piensan y se ven como sueños: asimetría de posiciones y de procesos que atraviesan tanto a uno como a otro.

Segundo, 1909: Freud, como espectador; parece que entre 1907 y 1909 y especialmente durante su viaje a los Estados Unidos, pudo asistir a algunas proyecciones de películas burlescas (cf. Jones); su actitud habría oscilado entre fascinación y desdén.

Tercero, 1936: Tomaremos el rumor añadido por JP Kameniak en 2015 a partir de las palabras de B Slarew: Freud habría sido visto en 1936 saliendo del Kreuzkino, un cine vienés, después de haber asistido a la proyección de películas policiales y/o westerns, Freud habría podido tener cierto interés en el cine como entretenimiento. 
Cuarto, 1925: Y, sin embargo, Freud se opone en varios fragmentos de textos y cartas al hecho de que el cine pueda servirse del psicoanálisis; no habría posibilidad de traducir el psicoanálisis como método y teoría a través del cine ya sea por su rechazo de contratos de la Goldwynn o por su crítica acerba del trabajo de Pabst en el que participaron Abraham y Sachs en 1925.

El contrapunto de este catálogo de cuatro fechas debería consistir en una larga evocación de la manera en que el psicoanálisis y, específicamente, su discurso, su método o sus actores fueron captados y propuestos por distintos cineastas en sus obras.

El "psicoanálisis en el cine" sería por sí solo un campo amplio y delicado que sólo vamos a tocar muy subjetivamente, pero lo remitiremos al trabajo sintético, por ejemplo, de Trichet y Marion en 2017 sobre la práctica analítica de Freud en la pantalla según Huston, Cronenberg y otros más.

Mencionemos solamente a seis directores. Cronológicamente: Pabst y los misterios de un alma, Buñuel y los olvidados, Hitchcock en varios fragmentos de $L a$ casa del Dr. Edwards o de Marnie, la ladrona, Bergman y las Fresas salvajes, entre otras y Huston por la biografía novelada del mismo Freud en el ahora famoso guión de Sartre en Freud, pasión secreta; incluso la polémica $U n$ método peligroso de Cronenberg.

Por interesantes que estos lineamientos puedan parecer no nos ayudan mucho en nuestra reflexión. Dejaremos entonces este campo para encarar otro nivel de análisis, el de la articulación entre cine y retórica.

\section{Del acontecimiento a la memoria: constitución de un discurso por una retórica}

Voy a instalar el término de retórica de manera central en mi propuesta. Defino la retórica a partir del triple esclarecimiento textual que proponen Arasse, Yates y Barthes.

Barthes entre 1964 y 1965 realizó su seminario sobre la retórica antigua (ver el texto que nos dejó en La aventura semiológica, entre otros).

Yates presentó en 1975 "el arte de la memoria", trabajo completo y rico sobre las formas y desafíos de la retórica.

Respecto a Arasse -que se revela como traductor de Yates- articula memoria y retórica en el proyecto de construcción de la pintura occidental a través de las figuras de la Anunciación.
Tomemos unos minutos para redefinir la retórica con ellos: para recordar un discurso y producirlo en cierta dirección, es necesario primero crear un lugar, un sentido de visita o de errancia en ese lugar y poblarlo de signos, de figuras, de formas notables como así también de “imágenes agentes”, es decir, imágenes sorprendentes. Es -hablando propiamente- poner en imágenes figuras del discurso, o localizar las figuras del discurso.

Los discursos que requieren este tipo de procedimiento son los que mencionan Arasse y Yates cuando hablan esencialmente de los discursos, ya sea políticos, o alegatos; es decir discursos de luchas, defensas, confrontaciones, denuncias, reivindicaciones; en una palabra, los sitúan como discursos de luchas.

Memorias y luchas son los significantes amo de este coloquio, proponemos que encuentren su confluencia y su articulación en un concepto, el de una Retórica.

El lazo entre retórica y psicoanálisis lo sostendremos más allá de la cercanía entre Barthes y Lacan o entre Arasse y Freud por el acercamiento conceptual entre, por un lado, la Retórica como operador de la constitución de imágenes y de figuras del discurso o más precisamente de la espacialización plástica de las figuras del discurso y, por otra parte, la transformación de un pensamiento en una situación que coincide con la exacta definición freudiana de la Figuración. Retórica y figuración son entonces conceptos que vamos a articular.

\section{Retórica y Figuración: \\ donde se encuentra todavía el prototipo del sueño, pero no solamente...}

La figuración o la consideración de la figurabilidad (Rucksicht auf darstellbarkeit en Freud) que a veces se lo traduce en francés por "dramatización" plantea la cuestión de la imagen y de las palabras y, más precisamente, de sus articulaciones (entre imágenes, entre palabras y entre ambos), es decir que esto moviliza lo que hace discurso. La figuración constituye un discurso y la retórica remite así a este despliegue de discursos que mezclan palabras e imágenes (imágenes agentes).

Sin embargo, no hay equivalencia estricta entre figuración y Retórica. La figuración es un proceso psíquico inconsciente claramente definido en la primera tópica freudiana; mientras que la retórica es una disciplina y un arte oratorio a la vez, arte oratorio que ocupa el campo de las figuras del discurso, pero, uno es leíble en el otro y este otro forma la base del primero. 
Un punto que me interesa particularmente aquí: la mostración (o la exposición) en sus diferencias respecto a la figuración; en cierta forma, esto puede constituir una fuerte distinción entre escena [scène] y obsceno [obscène].

Voy a dedicarme entonces a la parte de la memoria que requiere de la primera (la escena) y no de la otra (lo obsceno) y no podría volcar la ambición de la primera en lo que sobresale de la segunda. La memoria requiere, se entiende, una escena, incluso una puesta en escena (el prototipo sería el recuerdo-encubridor), pero, por otro lado, la memora no necesita de lo obsceno que sobresale y que se arruina en los efectos del surgir. ¿Cómo diferenciarlos y cómo entender a nuestros adolescentes captados por los efectos de las películas? ¿Habrán podido distinguir los dos niveles? ¿Pueden captar uno en el lugar del otro y reducir a lo obsceno lo que fue una escena o la potencia retórica de ciertas películas los protege de esto incluyéndolos en la escena por su mirada?

Para interrogar esto, tomemos la experiencia de nuestra clínica analítica y de nuestro humilde lugar de amateurs de cine para trazar algunas simetrías entre la retórica de la imagen y la retórica cinematográfica.

Comencemos entonces por la imagen en el sentido del cuadro y volvamos a la comodidad del texto de Arasse, por ejemplo, cuando analiza no solo la anunciación de Francesco del Cossa sino también las meninas de Velázquez, enmendando a Foucault.

La imagen se define por tres aspectos: por su marco, su composición y su motivo; el todo constituye una estructura formal que no se reduce a ninguno de esos tres aspectos pero produce la asunción de todos ellos.

Despejemos así las condiciones estructurales de la retórica de la imagen o a través de la imagen. Las condiciones de la figurabilidad que llamamos también las condiciones "altas" de la imagen son cuatro en total.

En principio, se necesita una semiótica, es decir un aparato de signos; luego, viene la constitución de escenas; en tercer lugar, todo esto se inscribe en un marco de la escena y, finalmente se ordena una retórica del encadenamiento de las escenas.

¿Cómo usa Arasse estas categorías necesarias, por ejemplo, en el análisis de las anunciaciones (momento evangélico en el que el arcángel Gabriel viene a anunciar a la virgen María que fue elegida entre todas las mujeres y que llevará a Cristo en su vientre)? En primer lugar, el aparato semiótico se detecta sucesivamente en el uso electivo del color azul para el manto de la virgen, el lirio blanco en la mano del arcángel, el libro que lee la virgen (evangelios de la vida del hijo por venir), el lugar de la columna o del pequeño muro que separa y une a la virgen y al arcángel y a muchos otros también.

En segundo lugar, la escena se produce fundamentalmente por la lateralización: lectura de izquierda a derecha por la aparición del arcángel a la izquierda del cuadro hacia la derecha donde está la virgen instalada y por la puesta en perspectiva de la columna y del pequeño muro, así como del jardín y de la habitación.

En lo que respecta al marco, este se ordena por los bordes del cuadro (y su inserción eventual, por ejemplo, el caracol de F. Del Cossa que se apoya sobre este borde del cuadro como figura pintada pero desfasado de la escena enmarcada) y se ordena también por la perspectiva y su profundidad que constituyen el campo de lo visible.

Finalmente, el cuarto componente, la retórica es a la vez interna al cuadro por la lectura del episodio evangélico, pero también está ligada a la puesta en serie de los cuadros en el centro, por ejemplo, de retablos en dípticos o trípticos o polípticos, tanto como por la inscripción de un espacio sagrado (el de la iglesia en donde los cuadros se responden) o en el recorrido del museo que puede incluso lindar con el museo imaginario en el sentido de Malraux al abrir la posibilidad de la constitución de un verdadero universo diegético de los cuadros (los cuadros ya no representan un mundo referencial sino que se remiten unos a otros en un juego de correspondencias internas al universo pictórico: Del Cossa aclarando Della Francesca que remite a Lorenzetti y esto sin límites de tiempo pero dentro de los límites de estructura).

No hay ninguna razón para que el cine escape a esta definición estructural de las condiciones de la figurabilidad. Si nos apoyamos en esta propuesta entonces sostendremos que la retórica construye las condiciones de una estética. Lo que vuelve a formular que la coherencia estructural de una película viene del despliegue y la articulación de las cuatro condiciones altas de la imagen, a saber: una semiótica, la constitución de escenas, el ordenamiento de marcos y el despliegue de una retórica. Sin insistir en esto, aclaremos que el aparato semiótico incluye los elementos filmados como las elecciones de colores como blanco y negro; en cuanto a la constitución de las escenas, las distribuciones de los elementos como las lógicas de campo y de contra-campo son necesarias; desde el punto de vista del marco, la especificidad de los planos como la articulación entre imagen y sonido es importante; finalmente (y es lo que nos interesa en este punto), la retórica. El operador retórico mayor del cine nos parece claramente ser el montaje. El montaje puede ser definido aquí como el uso de la diacronía para desviar el modo de percepción de la 
espacialidad de cada plano; es, además, una de las diferencias con los cuadros cuya diacronía es interna a la operación de lectura de la escena propuesta (ver la espacialidad de izquierda a derecha en las anunciaciones que permite pensar la diacronía de las palabras del arcángel dirigidas a la virgen); en cambio, en la operación cinematográfica, la diacronía está determinada, impuesta, casi forzada por el encadenamiento de los planos y las escenas. La retórica fílmica tiene entonces una potencia notable y esto permite interrogarnos nuevamente sobre la distinción entre escena y obsceno, incluso la distinción entre "puesta en escena(s)" y "posición obscena". La posición obscena puede ser definida metafóricamente como la moneda falsa de la escena, es decir que tiene la apariencia de un sistema simbólico de signos y de escenas instaladas en un marco, pero sus encadenamientos imponen, y lanzan al espectador una serie de fragmentos visuales sin construcciones, es decir sin fondo retórico. Las escenas chocantes y duras no son obscenas en sí mismas, lo son por no estar ordenadas ni narradas retóricamente. La retórica es un montaje, una diacronía que mantiene la escena en su valor pleno, mientras que lo obsceno está devaluado fuera de este valor pleno...

\section{Retórica, estética y luchas}

La estética contiene una retórica pero no se limita en absoluto a una deambulación formal avezada. La Ética se transforma en ese punto en una dimensión necesaria. La ética es el movimiento y la cualidad por la cual las figuras retóricas son la puesta en marcha y la implementación de los determinantes ideológicos.

Para apoyarnos en algún punto de familiaridad psicoanalítica en el cruce de Stein y de R. Gori, voy a resumir que la ética en psicoanálisis es la implementación de una teoría en un método. Usar esta fórmula en el campo fílmico permite proponer que la ética fílmica es la implementación de una ideología en una retórica de la imagen. Nunca hay ausencia ideológica, esta no cesa de trabajar profundamente la estética, ordenando los signos, supurando en los planos, cincelando los marcos y anudando los hilos del montaje.

Analizar la retórica de la imagen, del plano, de las secuencias es sacar a la luz las apuestas ideológicas de la superficie y darse la ocasión de leer los emergentes éticos de la película. ¿Qué es lo que distingue Noche y niebla de Olympia respecto al uso de la música, del montaje y de los travellings? ¿Qué es lo que en un análisis riguroso permitiría revelar que estas películas no se relacionan en absoluto en el mismo registro ideológico, en el cuerpo y sus ausencias, en la música y sus superposiciones con la imagen y que no corresponden a la misma ética en sus oposiciones estéticas? ¿Qué es lo que opone y articula $E l$ nacimiento de una nación y Acorazado Potemkin? ¿Son los primeros planos y los grandes planos generales, o la especificidad del montaje o las oposiciones ideológicas que encontrarían en los planos y la retórica fílmica sus antítesis? Serían necesarios muchos análisis que algunos colegas han o van a esbozar en este coloquio. Me limito aquí a afilar estas cuestiones hasta el filo de la siguiente fórmula: ¿las retóricas están sobredeterminadas ideológicamente?

Que las luchas en el sentido más social y político del término sean ideológicas las inscribe en aparatos de clasificación, de nominación y de asignación en el sentido muy preciso de la dependencia a un "orden del discurso" en el sentido que le asignaba Foucault en 1971. Desde este referente textual, tomémonos un tiempo para proponer un análisis y/o hipótesis estructural. Al menos, una lucha se inscribe en un esquema dual tanto como dialéctico en el que las oposiciones definen la cualidad de cada uno de los partidos y términos de la lucha; sin embargo, este esquema dual puede encararse también en un sistema de oposiciones de tres o cuatro términos.

Despejemos algunas fórmulas estructurales respecto a los nombres y articulaciones lógicas entre los términos lógicos de las luchas escenificables:

- los que hacen y aquellos a quienes se les hace

- aquellos que infligen y aquellos que sufren por ello

- quienes toman y a quienes se les saca

- los que se apenan y los que sacan provecho

- aquellos que transgreden y aquellos que hacen justicia

- aquellos que matan y aquellos que se vengan

No se le escapará al lector que el sentido dado a las luchas en sus determinaciones estructurales contiene ecos al final de la lucha de clases; ese no es un punto de extrema objetividad.

En términos psicoanalíticos, hagamos variar sutilmente la fórmula de la lucha insistiendo sobre las cualidades intrínsecas de la escena ordenada por y en la mirada:

- aquellos que vemos y aquellos por los que vemos

- lo que vemos y lo que ve

Estas fórmulas introducen al tema del punto de vista, desde la cuestión finalmente modificada de la perspectiva; incluso, nos conducirá a retomar la cuestión del 
punto de vista ideológico poniéndolo en resonancia con la cuestión del acontecimiento que sería el objeto de ese discurso y del locutor de todo discurso en sus lazos con la figura del narrador.

¿Entonces, desde dónde es vista la imagen? Foucault lo trabajó dos veces, por un lado, en su lectura de las Meninas (y Arasse lo mejoró) respecto a las condiciones de la representación, y, por otro lado, en su texto de 1960 L'arrière fable, donde indica que unas voces sin cuerpo se pelean para contar la fábula y aclara que no menos de cinco voces están presentes en el texto.

Las condiciones ideológicas y, en ese sentido, éticas de las representaciones son dependientes de las condiciones de movilización de un poder-saber por el ejercicio de una mirada. La voz del narrador no solo es una voz invocante, es también una voz ordenadora de la diacronía, es una voz que participa y que consiste en la retóri$\mathrm{ca}$, no es independiente del montaje, quizás incluso en el cine ella misma es el montaje... La estética limita con las múltiples miradas y con las múltiples voces al brindar su contenido en el dispositivo retórico.

Si no es seguro que haya una estética de la ética, ¡hay apuestas éticas e ideológicas en toda estética de la imagen fílmica!

La estética fílmica revela una política ya que necesariamente fue trabajada y atravesada por cuestiones éticas.

La película es un dispositivo (en el sentido de Agamben) y como tal se encuentra atravesado por los desafíos de poder y políticos.

Pero aquí me intereso menos en las palabras o en los temas enunciados en el dispositivo que en sus formas y en su estética, en la manera de declinar una semiología, un sistema de escenas, una lógica de marcos y una retórica.

Para enlazar con mi clínica de adolescentes impactados por películas, necesito examinar las condiciones de instalación y de determinación de la mirada. Mis adolescentes espectadores no tienen opción, serán inscriptos en los determinantes estéticos; están asignados a una posición que los intima respecto a lo que debe ser visto o no, cómo y en qué momento surgirá eso. La película, al ocupar el espacio y el tiempo, intensifica las condiciones de esta asignación, de ahí su potencia captadora pero también su posible oscilación entre la propuesta de las escenas y lo obsceno que sobresale de ellas.

El ojo de la cámara es el nombre que le doy a esta estética de la película y el medio que enuncia la ética de la película. El ojo de la cámara, lo pienso como lo que estructura la retórica de la imagen en una estética determinada y una posición ética posible pero no asegurada.
Barthes es muy útil para pensar las condiciones de la ética de un discurso; para sobrepasar y subvertir la dimensión normativa de los discursos, para desplazar sus efectos imperiosos recuerda en su lección inaugural del colegio de Francia que si la lengua está estructurada como un sistema de asignaciones, también conlleva la posibilidad de subvertir esas asignaciones a través de la literatura. La subversión también es la condición tanto de una estética como de una ética.

Si recuerdo que Simon, abrumado, habiendo agotado sus lágrimas y con la voz quebrada, quería repetirme y comentarme insistentemente los diálogos de Shoah. En este punto, puedo interrogarme sobre la fórmula estética y ética de Lanzmann en un movimiento que no consiste en hablar de los ausentes, sino más bien en cómo hablar del proceso que los vuelve ausentes y así ineludibles. La palabra que gira alrededor del vacío revela, por los bordes que cose [ourle] frente a la cámara, el perímetro de lo trágico. Esto en Lanzmann no es nada más que la subversión de lo que sería un discurso documental-histórico y constituye una ética de la palabra filmada que presenta las condiciones de la ausencia, encontramos en este coloquio el eco directo y estructuralmente homogéneo a la película presentada por Guillaume Moscovitz, Belzec, no porque el tema fuese homogéneo sino más bien porque la ética allí es transversal a los dos...

\section{El ojo de la cámara y la mirada a la cámara frente al adolescente}

Definí, unas líneas antes, el ojo de la cámara como: lo que estructura la retórica de la imagen en una estética determinada y una posición ética posible pero no asegurada. Por el ojo de la cámara, como narrador, existe un punto de vista que ordena simultáneamente un universo de signos, los movimientos de la escena, los límites de su marco y la retórica que sostiene todo el conjunto. Este ojo supone captar, instalar, revelar y hacer surgir otro ojo u otra mirada.

\section{Esta otra mirada, fórmula que tomo de Marc Vernet de su texto de 1983, "Mirada a la cámara”.}

Para Vernet es claramente una figura de la imagen fílmica que, al adosarse al marco y al abrirse hacia nosotros (espectadores) nos mira, nos mira a nosotros, nosotros que la miramos a los ojos desde la sala de cine. 
La mirada a la cámara pone en cuestión los efectos de nuestra mirada: ¿quién mira a quién? ¿qué función tiene la mirada de uno en la mirada del otro? Esto permitió desarrollos interesantes de Vernet sobre el sujeto-espectador. Esto tiene su equivalencia en Foucault con las Meninas cuando la mirada del pintor se apoya sobre nosotros, los espectadores de la tela y vuelve a interrogar qué es la tradición de los retratos en pintura y define también las condiciones de la representación.

Por la mirada de una figura podemos estar revelados en nuestra mirada; esto es una operación ficcional de engranaje que moviliza las formas de la mise en abyme como así también la inversión de las miradas. Nuestra posición en la mirada es revelada por el artefacto de la mirada a la cámara, sobre el modo de un surgimiento, de un giro de 180 grados.

¡No se trata de un espejo, sino de una ficción!

El valor de esta ficción se deduce de su potencial respecto al surgimiento de los procesos identificatorios y de los múltiples movimientos voyeristas como de exhibición.

$\mathrm{Si}$, en el contexto de los análisis de películas y de la puesta en tensión con el psicoanálisis, se vislumbra el interés de una noción como la de "mirada a la cámara", es necesario también tratar de inscribirlo como contrapunto dialéctico con el ojo de la cámara. El ojo de la cámara y la mirada a la cámara están situados en este texto como resortes dialécticos de los procesos adolescentes implicados en el desasosiego y el modo en el cual nuestros pacientes nos hablan de las películas.

El ojo de la cámara se les revela a mis adolescentes por los efectos de mirada a la cámara. Sin embargo, esta "mirada a... la cámara" o "mirada a... otro" no se limita a la notable precisión de lo que Vernet propone. En este texto, trato de desplazar la cuestión del primer vistazo del actor que tomaría al espectador hacia otro reto: ¿cómo el adolescente se siente visto por la película y se presta a interpretar [entendre] (en la transferencia) en las sesiones posteriores?

Para mí, entonces, la mirada a la cámara se acerca a lo que mis adolescentes me dicen: "ahí, los prisioneros te miran", "las fotos filmadas pareciera que están ahí en tus ojos", "la imagen me rompe la cabeza, toda la cabeza...", "ya no sé, no sé, es como si decidiera no mirar, y ahí, delante mío eso me mira, en realidad, sólo me mira a mí...”.

En la clínica de sujetos adolescentes, estas fórmulas enunciadas definen para mí una ligera variación: la mirada a través de la cámara.

Pasar de la "mirada a la cámara" a la "mirada a través de la cámara” es plantear que, clínicamente, existe un modo de captación por la retórica de la imagen que define una procesualidad [processualité] psíquica singular potencialmente adolescente.

En la mirada a través de la cámara, es una mirada desde la película que revela las condiciones de su mirada sobre la película y abre la recuperación de este movimiento en terapia, en sesión, en situación analítica y bajo transferencia.

Las condiciones de revelación [dévoilement], de descubrimiento del sujeto adolescente en el trabajo analítico encuentran un eco interesante en esta fórmula de la mirada a través de la cámara; de hecho, por poco que el sujeto "esté" en este "ojo" de la cámara, en ese momento invoca muy rápidamente las condiciones de un universo diegético. En este universo, la película responde a otras películas como a recuerdos y a momentos de sesiones. Hay un mundo que el sujeto mira sin ver y que, por momentos, surge y nos ve; entonces, el sujeto siente su propio lugar en la mirada.

Una de las fórmulas posibles que sería nuestra hipótesis central se enuncia así: mientras el espectador-sujeto está habitualmente captado por la mirada a la cámara; por el contrario, la mirada a través de la cámara se convierte en una mirada en la que el ojo del adolescente se exhibe ¡en el mismo lugar de la mirada de la película!

El ojo de la cámara puede ordenarse de varias maneras sobre la continuidad identificatoria y voyerista. En un extremo, esta mirada es la condición de la inmersión en la película, mientras que, en el otro extremo, esta mirada se transforma en el intersticio, el segmento, la fisura por donde se ve y se pesca la escena.

\section{La mirada a través de la cámara y los procesos adolescentes}

Plantearé ahora que en la dinámica de los procesos psíquicos adolescentes que van más allá del período de la adolescencia, lo que está en juego respecto de las continuidades identificatorias y voyeristas son particularmente importantes. La mirada a través de la cámara parece ser entonces, en un momento del trabajo analítico, aquello que se destaca.

La mirada a través de la cámara permite, entre otras cuestiones, interrogar los efectos en los adolescentes de la distinción entre escena y obsceno antes evocada. Lo que, de entrada, parecía satisfactorio y que estaría atravesado por la lógica de constitución de las escenas con especial empatía, compasión, deber de la memoria 
y toma de consciencia de las luchas y de sus efectos, se opondría a un cine que impone las formas del voyerismo con su cortejo de crudeza, de espectacularidad, de competencia, de repetición de dispositivos de sujeción [assujetissement] a la figura vista. Así, la escena estaría llevada por las formas identificatorias y lo obsceno por el flujo del voyerismo. Sin embargo, esto me parece caricatural y no parece justo con la complejidad de los procesos psíquicos.

Siguiendo a Freud, la lógica analítica nos empuja a plantear que el sujeto-espectador se encuentra necesariamente articulado tanto a una dinámica de identificación como a una dinámica voyerista y que son las articulaciones y variaciones dialécticas que determinan la singular posición del sujeto. Parece entonces pertinente distinguir radicalmente, por un lado, la lógica de los procesos psíquicos identificatorios y voyeristas y, por otro lado, la distinción ya impresa de los cuestiones éticas y estéticas de la escena opuesta a lo obsceno. Esto contiene la enorme ventaja clínica de plantear incesantemente el valor y la función de las películas evocadas, narradas y convocadas en las sesiones bajo transferencia.

Sin embargo, el razonamiento todavía está incompleto, el recurso a la mirada a través de la cámara lleva a profundizar las articulaciones conceptuales. El sujeto-espectador en el ojo de la cámara se revela de algún modo "bajo" la mirada a través de la cámara y/o bajo la mirada a la cámara. Esta posición indisoluble de una forma estética dada por el dispositivo cinematográfico permite entonces una triple función identificatoria y voyerista a la vez (ya lo dijimos) pero también exhibicionista dado que el adolescente se expone a la imagen que "lo mira".

Quisiera agregar un cuarto término, una faceta suplementaria que apela a otro proceso. Porque está sobre el eje ojo-mirada, el sujeto-espectador no solo moviliza identificaciones, sino que proyecta también determinantes de su escena psíquica en la película. No hace más que reconocerse o desconocerse en su descubrimiento escópico. El sujeto-espectador se revela en la mirada a través de la cámara por el apilamiento de material filmado de lo imaginario.

Por proyección, entendemos este proceso psíquico freudiano (y no este mecanismo de defensa del yo anna-freudiano) de atribución de un afecto al otro y, a la vez, la posible modalidad de una inversión, de un vuelco oposicional y de una transformación de este afecto.

Desembocamos entonces en una cuadrilla conceptual de dos dúos: voyerismo-exhibicionismo, lógicamente articulados en sus efectos de inversión; y también, identificación-proyección que distribuyen sobre el eje de la mirada a la cámara y a través de la cámara las formas de inscripción en la retórica de la imagen fílmica.

Los procesos adolescentes, dado que son estrechamente dependientes de los movimientos de esta cuadrilla conceptual, nos llevan a pensar el intenso valor de surgimiento de la retórica de la imagen cuando esta es convocada en sesión. Será en otra ocasión que podremos pensar rigurosamente los determinantes entre la retórica de la imagen y la dinámica de la transferencia.

Sin embargo, el ojo de la cámara y la mirada a través de la cámara son fórmulas que definen la operación de despliegue de la interlocución en sesión. El ojo supuesto, convocado por las películas evocadas por los adolescentes, se duplica con la oreja del analista necesaria y convocada por los cuestionamientos que surgen.

¿Quién escucha y quién mira a quién? En el espacio incierto de despliegue de los decires [dires] del sujeto y desde las referencias a las películas mencionadas, me interesa lo que insiste en y por el surgimiento y el subrayado de esta "mirada a través de la cámara" de estos procesos psíquicos adolescentes. Esta mirada a través de la cámara está anudada a la transferencia, me parece necesario interrogarla y subrayarla en un momento clínico en el que las cosas "con imágenes" [imagées] ocupan masivamente la vida de los sujetos.

Con Natacha, Alfred, Akira, Mylène, Simon y Mélanie, diviso y oigo, a veces, cómo los atrapa el deseo.

Las películas que ellos invocan, que vi en su mayoría, no son sin embargo las mismas que yo vi.

¿Qué presenta la película frente a nuestra mirada? ¿Una retórica que sustituye a nuestro mundo escenas que sostienen nuestros deseos?

Al menos, aquí intenté comprender cómo la proyección de películas, proyección en la película, proyección deseante, con todas sus inequivalencias significantes me permiten y me obligan a pensar en una articulación conceptual y metodológica de la palabra de los adolescentes. Este recurso sucesivo a expresiones tales como el ojo de la cámara, la mirada a la cámara y la mirada a través de la cámara son testigo de la necesidad de pensar que en la invocación del mundo de los relatos fílmicos y del lugar del ojo hay algo que es significante y deseante a la vez.

Traducción: Noelia Luzar 


\section{Referencias}

Aumont, J. ; Marie, M. 1988. L’analyse des films [El análisis de las películas], Paris, Nathan.

Alberti, L.B. 1868. De pictura (1435), trad. del latín al francés por Claudius Popelin, Paris, A. Lévy.

Arasse, D. 1982. «Frances Yates et les labyrinthes occultes de l’histoire [Frances Yates y los laberintos ocultos de la historia] », Débat, 22, novembre, p. 41-48.

ARASSE, D. 1992. Le détail, pour une histoire rapprochée de la peinture [El detalle, para una historia cercana a la pintura], París, Flammarion.

Arasse, D. 2000. On n’y voit rien [No vemos nada]. Descriptions, Paris, Denoël.

Arasse, D. 2004. Histoires de peintures [Historias de pinturas], Paris, Denoël.

Barthes, R. 1966. «Introduction à l'analyse structurale des récits [Introducción al análisis estructural del relato]», Communications, $\mathrm{n}^{\circ} 8$, «L’analyse structurale du récit [El análisis estructural del relato] ». Paris, Seuil.

Barthes, R. 1977. Leçon [Lección], Paris, Le Seuil.

Bonnet, C. ; Pechikoff, S. 2011. «Roman adolescent et scènes pubertaires [Novela adolescente y escenas pubertarias] », Adolescence, $\mathrm{n}^{\circ} 78$, p. $787-800$.

Bonnet, C. ; Petit , L. ; Pasquier , A. 2014. «Portrait de l'adolescent en héros à la cicatrice [Retrato del adolescente como héroe a la cicatriz] », Psychologie clinique, $n^{\circ} 38$, p. 45-54.

Bonnet, C. ; Pechikoff , S. ; Petit , L. 2014. «De l'exposition du héros aux blasons du corps adolescent [De la exposición del héroe a los escudos del cuerpo adolescente] », Topique, n 126, p. 25-38.

Bonnet, C. 2001. Entre récit et douleur, psychopathologie des récits de plaintes, thèse de doctorat en psychopathologie [Entre relato y dolor, psicopatología de los relatos de quejas, tesis de doctorado en psicopatología], bajo la dirección del Pr R. Gori.

Del Volgo, M.-J.; Gori, R.; Poinso, Y. 1993. «Roman de la maladie et travail de formation du symptôme. Complémentarité des approches psychanalytique et médico-biologique [Relato de la enfermedad y trabajo de formación del síntoma. Complementariedad de las aproximaciones psicoanalítica y médico-biológica] », Psychologie médicale, 26, 14, p. 1434-1438. DUMEZIL, G. 1968. Mythe et épopée 1[Mito y epopeya 1], Paris, Gallimard.

Foucault, M. 1960. «L’arrière fable [Fábula] », Dits et écrits [Dichos y escritos], Paris, Gallimard.

Foucault, M. 1966. Les mots et les choses [Las palabras y las cosas], Paris, Gallimard.

Foucault, M. 1971. L’ordre du discours [El orden del discurso], Paris, Gallimard.

Freud, S. 1899. «Sur les souvenirs écrans [Sobre los recuerdos encubridores]», en Névrose, psychose, perversion, [Neurosis, psicosis y perversión] Paris, PUF, 1909, p. 113-132.

Freud, S. 1900. L'interprétation des rêves [La interpretación de los sueños], Paris, PUF, 1987.

Freud, S. 1901. Sur le rêve [Sobre el sueño], Paris, Gallimard, 1942.

Freud, S. 1901. Psychopathologie de la vie quotidienne [Psicopatología de la vida cotidiana], Paris, PBP, 1968.

Freud, S. 1905. Trois essais sur la théorie sexuelle [Tres ensayos sobre teoría sexual], Paris, Gallimard, 1962.

Freud, S. 1909. «Le roman familial des névrosés [La novela familiar de los neuróticos] », dans Névrose, psychose, perversion [Neurosis, psicosis y perversión], Paris, PUF, 1973, p. 157-160.

Gori, R. 1996. La preuve par la parole [La prueba por la palabra], Paris, PUF.

Gori, R. 1999. «Le rêve n'existe pas [El sueño no existe]», La science au risque de la psychanalyse [La ciencia a riesgo del psicoanálisis], Toulouse, érès.

Gori, R. 2001. «Les rhétoriques de la souffrance [Las retóricas del sufrimiento] », en Qu’est-ce qui guérit dans les psychothérapies [¿Qué es lo que cura en las psicoterapias?], Paris, PUF.

Gori, R. 2002. Logique des passions [Lógica de las pasiones], Paris, Denoël.

Kamieniak, JP. 2015. «L'image de la psychanalyse au cinéma [La imagen del psicoanálisis en el cine]», Topique. Revue freudienne, no 131, 2015. 